\title{
Differences in Proteomic Profiles Between Caries Free and Caries Affected Children
}

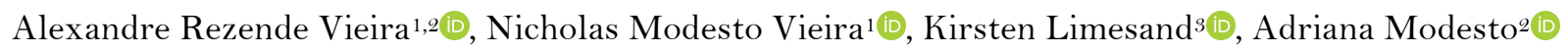

${ }^{1}$ Department of Oral Biology, School of Dental Medicine, University of Pittsburgh, Pittsburgh, PA, USA.

${ }^{2}$ Department of Pediatric Dentistry, School of Dental Medicine, University of Pittsburgh, Pittsburgh, PA, USA.

${ }^{3}$ Department of Nutritional Sciences, University of Arizona, Tucson, AZ, USA.

Author to whom correspondence should be addressed: Alexandre R. Vieira, Dept. Oral Biology, 412 Salk Pavilion, University of Pittsburgh Schoolof Dental Medicine, Pittsburgh, PA, USA 15261. Phone: +1 412-383-8972. E-mail: arv11@pitt.edu.

Academic Editor: Alessandro Leite Cavalcanti

Received: 07 April 2020 / Accepted: 15 June 2020 / Published: 09 July 2020

How to cite this article: Vieira AR, Vieira NM, Limesand KH, Modesto A. Differences in proteomic profiles between
caries free and caries affected children. Pesqui Bras Odontopediatria Clín Integr. 2020; $20: e 5592$.
https://doi.org/10.1590/pboci.2020.131

\begin{abstract}
Objective: To determine if there are differences in protein profiles in saliva depending if children of cariesfree versus caries affected. Material and Methods: A cohort of 91 children with ages between 6 and 19 years, along clinical status of caries experience. Protein profiles in saliva were determined using electrophoresis and the calculation of the percentage of a specific band at a specific molecular weight in relationship to the total protein in that sample (\% of total) using molecular weight standards. This quantification was repeated for each protein band across a range of molecular weights for each sample. Chisquare, Fisher's exact, and Student t-tests were used to compare the distributions between caries-free and caries affected children $(\alpha=0.05)$. Results: Histatin was more likely to be non-detectable or reduced in caries-free children (OR=7.56; 95\% CI 1.62-35.13) and these children had on average one less gel band detected by the assay we used. Conclusion: We have found differences in proteins between caries affected and caries-free children, suggesting that this line of investigation holds the promise of providing new tools for caries management.
\end{abstract}

Keywords: Dental Caries; Proteome; Proteomics; Saliva. 


\section{Introduction}

Blood has been the substance of choice for diagnostics. However, obtaining saliva has the advantage of being non-invasive in nature and saliva has been explored as a potential source for discriminating, detecting, and monitoring biomarkers. Published evidence suggests the identification of peptides in saliva may become a tool for determining disease risk and activity. However, except for Sjögren's syndrome, most studies of the same disease are conflicting in regard to the suggested saliva biomarkers [1].

For dental caries, levels of statherin (a protein that prevents precipitation of calcium phosphate) and a truncated cystatin $\mathrm{S}$ (a proteinase inhibitor) missing the first eight $\mathrm{N}$-terminal amino acids showed inversed correlation with dental caries experience [2]. Dental caries biofilm composition and protein relative abundance in the presence and absence of sucrose also showed promising results related to changes in protein relative abundance as indicators of dysbiosis [3].

In cases of severe early childhood caries, two segments of the histatin-1 (which exhibits antibacterial and antifungal activities) peptide can be detected in saliva by magnetic bead (MB)-based matrix-assisted laser desorption/ionization time-of-flight mass spectrometry (MALDI-TOF MS) [4]. Tandem mass spectrometry of saliva samples from individuals with dental caries showed overexpression of markers of the complement system and inflammation [5].

Further work suggests differences in the complexity of the proteins identified depending on whether samples come from individuals resistant or affected by dental caries [6]. This evidence suggests that there are differences in proteomic profiles of individuals affected or not by dental caries. Therefore, we aimed to test the hypothesis that differences in salivary peptides that can be useful for future research or clinical management of patients can be identified when unstimulated whole saliva is used.

\section{Material and Methods}

Study population

A cohort of 91 children with ages between 6 and 19 years were consecutively recruited for these analyses using the University of Pittsburgh, School of Dental Medicine, Dental Registry and DNA Repository project (University of Pittsburgh Institutional Review Board (IRB) approval \# 0606091).

This project was started in September 2006 and all the patients treated at the Dental Clinics of the University are invited to be part of the registry. All subjects provided written informed consent authorizing the extraction of dental and medical information from their records and provided a saliva sample for future studies.

Saliva samples were obtained prior to the subject's dental appointment and were frozen until analysis. Age, sex, ethnicity, caries experience in the primary dentition and caries experience in the permanent dentition were considered. Caries experience, measured as DMFT and DMFS (decayed, missing due to caries and filled teeth or surfaces) at the time of examination, was based on oral inspections and bite-wing radiographs and were collected from each participant's dental record, based on already existing values. Surfaces were defined as decayed if the carious lesions extended into dentine or were circumscribed to the dental enamel and appeared active (white spot lesions). Twenty children were caries-free and were compared to the remaining children with past caries experience.

Protein Profiling 
The collected saliva samples were evaluated using the Bio-Rad Experion Automated Electrophoresis System (Bio-Rad Laboratories, Inc., Hercules, CA, USA). Ten microliters of each saliva sample were loaded into a primed Experion Chip and run using the Experion Software Protein 260 Assay (Bio-Rad Laboratories, Inc., Hercules, CA, USA), as described previously [7]. The protein banding profile from each sample was used to generate a composite image similar to a Coomassie stain. Experion image analysis software calculated the percentage of a specific band at a specific molecular weight in relationship to the total protein in that sample (\% of total) using molecular weight standards. This quantification was repeated for each protein band across a range of molecular weights for each sample. Analysis of the 91 individuals was completed using bands located at or around certain molecular weights.

Data Analysis

Chi-square, Fisher's exact, and Student $t$-tests were used to compare the distributions between cariesfree and caries affected children $(\alpha=0.05)$.

\section{Results}

Children with caries experience were on average, four years older than children that comprised the caries-free comparison group, but their distribution of sex and ethnic background was not different. More children with caries-free permanent dentition had substantial caries experience (seven affected surfaces or more) in the primary dentition. Histatin was more likely to be non-detectable or reduced in caries-free children $(\mathrm{OR}=7.56 ; 95 \% \mathrm{CI}$ 1.62-35.13) and these children had, on average, one less gel band detected by the assay we used. All detected proteins are listed in Table 1.

Table 1. Demographics, caries prevalence, and proteins identified in the study subjects.

\begin{tabular}{|c|c|c|c|}
\hline Variables & Caries Affected $(\mathrm{N}=71)$ & Caries Free $(\mathrm{N}=20)$ & p-value \\
\hline Age (Mean Years and Range) & $13.53(6-19)$ & $9.15(6-14)$ & $<0.00001^{*}$ \\
\hline \multicolumn{4}{|l|}{ Sex } \\
\hline Females & 33 & 10 & $0.78^{\#}$ \\
\hline Males & 38 & 10 & \\
\hline \multicolumn{4}{|l|}{ Ethnicity } \\
\hline Blacks & 16 & 4 & $0.92^{\#}$ \\
\hline Whites & 40 & 11 & \\
\hline Others & 15 & 5 & \\
\hline DMFT (Mean and Range) & $4.82(1-17)$ & o & \\
\hline DMFS (Mean and Range) & $8.9(1-41)$ & o & \\
\hline $\begin{array}{l}\text { High Caries Experience in the Primary Dentition with } \\
\text { dmfs } 7 \text { or Higher }(\mathrm{N})\end{array}$ & 13 & 11 & $0.001^{\#}$ \\
\hline Amylase not Detected or Reduced (N) & 3 & o & $0.21^{\&}$ \\
\hline Agglutinin not Detected or Reduced (N) & 20 & 3 & $0.23^{\&}$ \\
\hline Histatin not Detected or Reduced (N) & 3 & 5 & $0.01^{\&}$ \\
\hline $\begin{array}{l}\text { Presence of Proteins with Molecular Weight Smaller } \\
\text { Than } 1 \mathrm{KDa}(\mathrm{N})\end{array}$ & 48 & 11 & $0.3^{\#}$ \\
\hline Number of Bands in Gel (Mean and Range) & $8.93(3-14)$ & $7.85(4-12)$ & $0.03^{*}$ \\
\hline
\end{tabular}

"t-test; \#Chi-square; \&Fisher's exact.

\section{Discussion}

Dental caries continues to affect a large segment of the population, but its epidemiology has changed from affected essentially everyone to pockets of people who are caries-free and individuals at higher risk that 
experience most of the disease in the population [8]. Although preventive measures such as school-based sealant applications, fluoride exposure of the population through toothpastes or fluoridated drinking water, and facilitation of access to dental care played an important role in reducing caries experience globally, a segment of the population remains experiencing dental caries, which justifies research taking advantage of the molecular knowledge gained in the last decades. Genomic approaches have been considered as potential tools in helping determining dental caries risks [9,10], as well as evaluations that take advantage of longitudinal assessments of the disease to determine disease trajectories [11].

Proteomic approaches are emerging in oral health and the combination of the easiness of obtaining saliva and investigating a disease highly prevalent such as dental caries provide an opportunity to perform proteomic studies in cariology. Since the disease affected the hard structures of the mouth, which are washed by saliva, it is reasonable to believe that saliva will reflect dental caries activity. We have shown that differences between individuals affected by dental caries and caries-free people exist, which agrees to previously published work [1,2,4-6].

Our sample is a little more robust than previous studies but has some interesting aspects such as a relevant frequency of more severe caries experience in the primary dentition in particular in the children that was included in the caries-free group. It is difficult to speculate if this would necessarily impact our results. The technology we used is simpler than other studies. This brings up the possibility that this kind of approach can be one day translated to clinical practice and used as a tool for decision-making regarding clinical care.

\section{Conclusion}

We have found differences in proteins between caries affected and caries-free children, suggesting that this line of investigation holds the promise of providing new tools for caries management.

\section{Authors' Contributions}

\begin{tabular}{|c|c|c|}
\hline ARV & (D) $0000-0003-3392-6881$ & $\begin{array}{l}\text { Conceptualization, Methodology, Formal Analysis, Resources, Data Curation, } \\
\text { Writing - Original Draft Preparation, Writing - Review and Editing, } \\
\text { Visualization, Supervision, Project Administration and Funding Acquisition. }\end{array}$ \\
\hline NMV & (iD) $0000-0001-5971-652 \mathrm{X}$ & $\begin{array}{l}\text { Formal Analysis, Data Curation, Writing - Original Draft Preparation and } \\
\text { Visualization }\end{array}$ \\
\hline KL & (iD) $0000-0003-4295-4665$ & Investigation, Data Curation and Writing - Original Draft Preparation. \\
\hline AM & (iD) $0000-0003-4414-069 \mathrm{X}$ & $\begin{array}{l}\text { Methodology, Resources, Writing - Original Draft Preparation, Supervision, } \\
\text { Project Administration, Funding Acquisition }\end{array}$ \\
\hline
\end{tabular}

\section{Financial Support}

None.

\section{Conflict of Interest}

All authors declare that there are no conflicts of interests related to the present article.

\section{References}

1. Al-Tarawneh SK, Border MB, Dibble CF, Bencharit S. Defining salivary biomarkers using mass spectrometry-based proteomics: a systematic review. OMICS 2011;15(6):353-61. https://doi.org/10.1089/omi.2010.0134

2. Rudney JD, Staikov RK, Johnson JD. Potential biomarkers of human saliva function: a modified proteomic approach. Arch Oral Biol 2009; 54(1):91-100. https://doi.org/10.1016/j.archoralbio.2008.08.007 
3. Rudney JD, Jagtap PD, Reilly CS, Chen R, Markowski TW, Higgins L, et al. Protein relative abundance patterns associated with sucrose-induced dysbiosis are conserved across taxonomically diverse oral microcosm biofilm models of dental caries. Microbiome 2015; 3:69. https://doi.org/10.1186/s40168-015-0136-Z

4. Sun X, Huang X, Tan X, Si Y, Wang X, Chen F, et al. Salivary peptidome profiling for diagnosis of severe early childhood caries. J Transl Med 2016; 14(1):240. https://doi.org/10.1186/s12967-016-0996-4

5. Belstrøm D, Jersie-Christensen RR, Lyon D, Damgaard C, Jensen LJ, Holmstrup P, et al. Metaproteomics of saliva identifies human protein markers specific for individuals with periodontitis and dental caries compared to orally healthy controls. Peer J 2016; 4:e2433. https://doi.org/10.7717/peerj.2433

6. Wang K, Wang Y, Wang X, Ren Q, Han S, Ding L, et al. Comparative salivary proteomics analysis of children with and without dental caries using the iTRAQ/MRM approach. J Transl Med 2018; 16(1):11.

https://doi.org/10.1186/s12967-018-1388-8

7. Grundmann O, Fillinger JL, Victory KR, Burd R, Limesand KH. Restoration of radiation therapy-induced salivary gland dysfunction in mice by post therapy IGF 1 administration. BMC Cancer 2010; 10(1):417.

https://doi.org/10.1186/1471-2407-10-417

8. Tickle M. The 80:20 phenomenon: help or hindrance to planning caries prevention programmes? Community Dent Health $2002 ; 19(1): 39-42$.

9. Vieira AR, Modesto A, Marazita ML. Caries: review of human genetics research. Caries Res 2014; 48(5):491-506. https://doi.org/10.1159/000358333

10. Nibali L, Di Iorio A, Tu YK, Vieira AR. Host genetics role in the pathogenesis of periodontal disease and caries. J Clin Periodontol 2017; 44(Suppl 18):S52-S78. https://doi.org/10.1111/jcpe.12639

11. Weber M, Søvik JB, Mulic A, Deeley K, Tveit AB, Forella J, et al. Redefining the phenotype of dental caries. Caries Res 2018; 52(4):263-71. https://doi.org/10.1159/000481414 